\title{
Perceptions of Practice Among Rural Family Physicians-Is There a Gender Difference?
}

\author{
Michelle L. Spenny and Katbleen E. Ellsbury, MD, MSPH
}

Background: Women physicians are relatively less likely to practice in rural areas. The purpose of this study was to describe differences in perceptions of rural practice between male and female physicians currently in rural practice.

Methods: A questionnaire was developed from interviews with rural family physicians and mailed to 118 randomly selected board-certified family physicians in rural towns of the northwestern United States.

Results: Responses from 63 physicians were analyzed quantitatively and qualitatively. Female family physicians were more likely than their male counterparts to agree they had been attracted by the availability of part-time work and by opportunities for their personal partner. Compared with men, women were more likely to expect to earn less in rural than in urban practice. On open-ended questions analyzed using qualitative methods, women were more likely to report discouragement by professional isolation and by potential lack of privacy in rural areas.

Conclusions: These responses suggest that during recruitment efforts rural communities might be able to attract more female physicians by offering flexible schedules, spouse or partner opportunities, role boundaries, and professional or personal support networks. (J Am Board Fam Pract 2000;13: 183-7.)

Although the shortage of physicians in rural communities has been well described, little work has been published on why women do not enter rural practice in greater numbers. Women make up an increasing proportion of US physicians. ${ }^{1}$ Most rural physicians are trained in family practice, and increasing proportions of female medical students are choosing family medicine as a specialty. ${ }^{2,3}$ Even so, the ratio of male to female physicians in rural areas is quite high-7.6 to 1 in nonmetropolitan areas. ${ }^{4}$ Several factors could explain these patterns.

Physicians often cite the problem of long work hours as a negative attribute of rural practice. ${ }^{5}$ In one study the work week of rural family physicians was 7 hours longer than that of urban family physicians, with more time spent on call. ${ }^{6}$ Overall, female physicians work fewer hours and are more likely to work part-time and spend less time on call than male physicians, ${ }^{5,7-9}$ but part-time practice appears to be difficult to maintain in rural areas.

Submitted, revised, 5 January 2000.

From the Department of Family Medicine (MLS, KEE), School of Medicine, University of Washington, Seattle. Address reprint requests to Kathleen E. Ellsbury, MD, MSPH, Department of Family Medicine, Box 356390, University of Washington, Seattle, WA 98195-6390.

This research was supported through the WWAMI Rural Health Research Center.
Thus, the relatively long hours of rural practice and the difficulty of succeeding in a part-time practice might make rural practice less attractive than urban practice to young physicians, especially female physicians.

Another issue in rural practice is that of relatively lower provider compensation rates compared with those of urban areas. Rural physicians are reimbursed at lower rates by such federal programs as Medicare. ${ }^{10}$ One study concluded that lower reimbursement was the greatest barrier to recruitment and retention of primary care physicians in rural areas. ${ }^{5}$ Whether reimbursement issues in rural areas influence male and female physicians differently, however, is not well described,

The ability to separate work and personal life has been shown in past studies to be important for physicians, especially for women. Female physicians are more likely than male physicians to serve as primary caregivers for their families. This added responsibility can introduce role strain and could explain some of the practice choice differences between male and female physicians. ${ }^{7,8,11,12}$ More than one half of female physicians in one study considered parental responsibilities to have a major effect on the time they devoted to their medical practices. ${ }^{11}$ In one study, more than $95 \%$ of hus- 
bands of female physicians worked outside the home, and many altered their career pathway when their wives chose rural practice. In another study of female general practitioners, a job's interference with family life was a strong predictor of job dissatisfaction. ${ }^{12}$ Thus, if role strain is greater where the boundaries between work and family life are blurred, then rural practice could create relatively more role strain and thus more dissatisfaction among female physicians compared with male physicians in rural areas.

Finding the right practice structure is another challenge for physicians considering rural practice. The difficulty in locating a stable practice with enough family physicians willing to form a group could prevent some women from moving to rural areas. In one regional study, nearly all the graduates from family practice residencies who were working in rural areas chose private practice. ${ }^{6}$ In another study of family medicine residency graduates, physicians who chose rural settings were more likely than those in urban settings to work in solo practice. ${ }^{13}$ Women are less likely than men to choose solo practice, however. ${ }^{79}$ Rural physicians are more likely than urban physicians to perform both hospital- and office-based procedures, spend more time in hospital settings, and to hold more medical privileges. Although it is difficult to generalize study findings from one country to another, it was found in one Australian study that female physicians spent less time in hospitals and did fewer procedures than did male physicians. ${ }^{14}$ Thus, several aspects of practice (private practice, solo practice, and procedure-oriented practice), all more common in rural than urban areas, might hold relatively less appeal for female physicians.

Finally, partner and spouse issues also differ for male and female physicians. Spouses of female physicians are more likely to hold advanced degrees and work full-time than are spouses of male physicians. ${ }^{15,16}$ Opportunities for spouses with advanced degrees might be more limited in rural than in urban areas.

The purpose of our study was to investigate, by comparing perceived attributes of rural practice, whether factors attracting and retaining rural family physicians differed by physician gender.

\section{Methods}

\section{Instrument}

To design a study instrument, we conducted semistructured telephone interviews with 5 male and 5 female rural family physicians on the University of Washington clinical faculty roster for Idaho, Montana, and Wyoming. The interviewer (MS) inquired about each physician's motivation to practice in a rural area, practice satisfaction, and demographic information. Interviewee responses, along with a literature search of similar studies, were used to create a pilot questionnaire. This questionnaire elicited demographic information and asked respondents to rate their level of agreement with statements regarding satisfaction with their current practice. The pilot questionnaire was mailed to 29 randomly selected rural Washington physicians listed in the American Board of Family Practice 1997 Diplomate Directory who had addresses in towns of less than 10,000 residents with fewer than 15 directory listings for each of those communities.

We used responses from the pilot survey to modify the instrument and create a 2-page questionnaire with both quantitative and qualitative question structures. The quantitative portion inquired about each physician's level of agreement with statements regarding characteristics of rural practice and his or her decision to practice in a rural community. It also elicited demographic and spouse or partner information. The qualitative portion contained open-ended questions about perceived positive and negative aspects of rural practice.

\section{Participants}

The questionnaire was mailed in August 1997 to 118 physicians in rural communities in Idaho, Montana, and Wyoming. Rural communities in these states were defined as having a population of 10,000 or less according to the 1990 US Census. Because of few female physicians practicing in rural areas, all 46 qualifying females were included in the sample. As a comparison group, 57 male physicians were randomly selected from 228 rural male physicians meeting all selection criteria and who practiced in one of the same three states. In addition, 15 androgynous names were included and the sex of the respondents was determined from their responses to a sex-specific item on the questionnaire. Three weeks after the initial mailing, we sent a second mailing to nonrespondents.

Responses to quantitative items were coded and analyzed using the Statistical Science Package for the Social Sciences. ${ }^{17}$ Students' $t$ test for difference 
Table 1. Family Physician Levels of Agreement to Statements Regarding Rural Family Practice.

\begin{tabular}{|c|c|c|c|c|}
\hline \multirow[b]{2}{*}{ Statements } & \multicolumn{3}{|c|}{$\begin{array}{c}\text { Median Scores Indicating Level of } \\
\text { Agreement* }\end{array}$} & \multirow[b]{2}{*}{$\begin{array}{c}P \\
\text { Value }\end{array}$} \\
\hline & $\begin{array}{c}\text { All } \\
\mathrm{n}=63\end{array}$ & $\begin{array}{c}\text { Male } \\
\mathrm{n}=37\end{array}$ & $\begin{array}{l}\text { Female } \\
\mathrm{n}=26\end{array}$ & \\
\hline $\begin{array}{l}\text { It is important that I feel well-integrated socially into the } \\
\text { rural community in which I work }\end{array}$ & 1.87 & 1.78 & 2.00 & NS \\
\hline $\begin{array}{l}\text { It is important to me to have my off-duty hours free from } \\
\text { work-related issues }\end{array}$ & 1.50 & 1.56 & 1.42 & NS \\
\hline $\begin{array}{l}\text { The attractive characteristics of the community in which I } \\
\text { chose to practice were important to my decision to } \\
\text { practice in a rural area }\end{array}$ & 1.73 & 1.72 & 1.73 & NS \\
\hline $\begin{array}{l}\text { The attractive characteristics of the practice were important } \\
\text { in my decision to move to a rural area }\end{array}$ & 1.81 & 1.86 & 1.73 & NS \\
\hline $\begin{array}{l}\text { The opportunity to make many clinical decisions } \\
\text { independently is important to my practice }\end{array}$ & 1.77 & 1.69 & 1.88 & NS \\
\hline $\begin{array}{l}\text { My spouse/partner had to consider altering his/her career } \\
\text { path when we were contemplating moving to a rural area }\end{array}$ & 2.83 & 2.93 & 2.67 & NS \\
\hline $\begin{array}{l}\text { The lack of spouse/partner was a deterrent in my making a } \\
\text { decision to practice in a rural area }\end{array}$ & 3.29 & 3.67 & 3.00 & NS \\
\hline
\end{tabular}

*Scores range from $1-4$, with 1 = strongly agree, 2 = agree, $3=$ disagree, 4 = strongly disagree. NS = no significant difference.

between means was used to compare men's and women's responses.

We coded the open-ended questions regarding most positive and negative aspects of rural practice using a qualitative method adapted from that of Glaser. ${ }^{18}$ We did not know the sex of respondents when coding responses to these open-ended questions.

\section{Results}

Of the 118 questionnaires mailed, 104 apparently reached their destinations; 2 were returned without forwarding addresses, and 12 were returned unanswered. Of these $104,63(61 \%)$ had useable responses. Response rates were as follows: 33 of 57 $(58 \%)$ of male names, 22 of $46(49 \%)$ of female names, 8 of $15(53 \%)$ of androgynous names (of whom 4 were male and 4 were female). Thus the respondent group was comprised of $37(59 \%)$ men and $26(41 \%)$ women.

\section{Quantitative Analysis}

Female respondents were younger (mean age 39 vs 43 years for male respondents), were less likely to be married $(77 \%$ vs $97 \%$ ), had finished residency more recently ( 7 vs 14 years ago), and had fewer years in practice ( 5 vs 12 years) and in their current location (4 vs 9 years) than male respondents. Questionnaire items (Table 1) that included a nu- meric rating scale were analyzed using quantitative techniques. Women were significantly more likely than men to agree with several statements, including, "Having the option of working part-time is important to me" $(P<.001)$, "I expected to earn less in a rural community than I could have earned in a more urban area" $(P<.05)$, and "My spouse's/ partner's ability to obtain employment or education played an important role in my choosing a rural community in which to practice" $(P<.001)$.

There were no significant differences between male and female respondents with regard to 21 of 24 questionnaire statements. These statements related to work hours ("It is important to me to have my off-duty hours free from work-related issues"), practice structure ("Administrative issues are a negative aspect of my job," and "Having a practice in which I can perform many medical procedures is important to me"), role strain ("I am bothered by the amount of privacy I have lost by working in a rural area"), and partner issues ("The lack of a spouse/partner was a deterrent in my making a decision to practice in a rural area"). Also not significantly different by gender were the following statements: "It is important that I feel well-integrated socially into the rural community in which I work," and "The attractive characteristics of the community in which I chose to practice were important in my decision to practice in a rural area." 


\section{Qualitative Analysis}

The second segment of the questionnaire requested written answers to open-ended questions eliciting the most positive and negative aspects of rural practice. Regarding the most positive aspect of rural practice, written responses were grouped into two general categories: quality of life and rural practice characteristics. The majority of both men $(62 \%)$ and women (88\%) wrote comments related to quality of life as opposed to rural practice characteristics. Examples of such comments included, "no congestion, no lines, and nice people," "I like small towns and farm communities," and "living where people are not strangers and there is an atmosphere of trust."

Regarding the most negative aspects of rural practice, men and women differed in some respects. The greatest proportion of the men $(30 \%)$ mentioned long hours, including such examples as "burnout from excessive call," "overwork," and "excess hospital and ER demands." Relatively greater proportions of women raised concerns about the lack of privacy in the community $(30 \%)$ or personal and professional isolation (31\%). Examples of the comments included: "can't escape patient phone calls unless I go out of town," "lack of socialization with other professionals," and "the community's unrealistic expectations of being 24 hours on call."

\section{Discussion}

The results of this regional study, using both quantitative and qualitative approaches, suggest that a few gender differences exist in family physicians' perceptions of rural practice. Men and women differ with respect to three factors: preference for part-time work, anticipated earnings, and partner or spouse employment opportunities.

The differences between male and female family physician practice preferences correspond well with past observed differences between male and female family physicians. Previous studies have shown that compared with male physicians, a greater percentage of female physicians work part-time. ${ }^{8}$ Similarly, our study showed that rural female physicians are more likely than their male counterparts to value part-time employment, suggesting that shortages of part-time practice opportunities in rural communities might discourage female physicians from considering entering or staying in rural practice. Although women in urban and rural are as likely to hold the same preference for part-time work, flexible hours, and partner opportunities, the relative lack of such options in rural areas can discourage women more than men.

In this study female family physicians were more likely than male family physicians to agree with the statement that they "expected to earn less in a rural community than in a more urban area." It could be that male physicians are aware of this income discrepancy but they are more willing to increase their work hours to compensate for this difference in reimbursement.

Becoming an integral part of the community appears to be a desire of many physicians, especially women. A close relationship with the community, however, could be coupled with a loss of privacy. Telephone conversations and written comments from several female physicians suggested that lack of privacy was a source of some concern. At the heart of this issue seems to be the expectations of some rural communities that a physician be available after hours. The challenge for small towns is to allow physicians to integrate into their communities without denying them privacy and personal time. It might be that women guard their privacy more vigilantly because of multiple demands on their time.

The limits of this study include the nature of its design, the reliance on subjects' self-report and reflection, the low response rate, the regional nature of the study, and that it examined only family physicians. It also did not examine physicians who left rural practice. Nonrespondents might have differed in some respects from respondents, reflecting inaccurately the perceptions of rural physicians as a group. It is difficult to assess, however, whether respondents' perceptions of rural practice would be more positive, more negative, or relatively similar to those of nonrespondents.

Based on their responses to open-ended questions, role stress appears to be a concern for some rural physicians, especially women. Respondents' comments parallel findings of previous studies showing that many women perceive themselves as primarily responsible for home life and encounter role stress when professional life competes with personal life. ${ }^{11,12,15}$ It is interesting that women had a somewhat lower response rate than men, perhaps because they had less time to respond to a questionnaire. Women's lower response rate might 
have contributed to an underestimate of gender differences on responses.

Despite these limitations, this study provides some insights into how rural male and female physicians' perceptions differ. These perceptions relate, in turn, to physician satisfaction. Because a powerful relation exists between job dissatisfaction and job turnover, ${ }^{19}$ information regarding physicians' levels of satisfaction could help attract and retain more female physicians in rural practice. Practices, communities, and recruiting firms should keep these factors in mind when recruiting rural physicians and configuring practice arrangements for physicians once recruited.

\section{References}

1. Cooper RA. Seeking a balanced physician workforce for the 21st century. JAMA 1994;272:680-7.

2. West PA, Norris TE, Gore EJ, Baldwin LM, Hart LG. The geographic and temporal patterns of residency-trained family physicians: University of Washington Family Practice Residency Network. J Am Board Fam Pract 1996;9:100-8.

3. Rosenblatt RA, Whitcomb ME, Cullen TJ, Lishner DM, Hart LG. Which medical schools produce rural physicians? JAMA 1992;268:1559-65.

4. Doescher MP, Ellsbury KE, Hart LG. The distribution of rural female generalist physicians in the United States. J Rural Health 1999, in press.

5. Forti EM, Martin KE, Jones RL, Herman JM. Factors influencing retention of rural Pennsylvania family physicians. J Am Board Fam Pract 1995;8:46974.

6. Baldwin LM, Hart LG, West PA, Norris TE, Gore $E$, Schneeweiss $R$. Two decades of experience in the University of Washington Family Medicine Residency Network: practice differences between graduates in rural and urban locations. $J$ Rural Health 1995;11(1):60-72.

7. Williams AP, Domnick-Pierre K, Vayda E, Steven- son HM, Burke $M$. Women in medicine. practice patterns and attitudes. CMAJ 1990;143:194-201.

8. Hojat M, Gonnella JS, Veloski JJ, Moses S. Differences in professional activities, perceptions of professional problems, and practice patterns between men and women graduates of Jefferson Medical College. Acad Med 1990;65:755-61.

9. Rosenthal TC, Rosenthal GL, Lucas CA. Factors in the physician practice location puzzle: a survey of New York State residency-trained family physicians. J Am Board Fam Pract 1992;5:265-73.

10. Rosenblatt RA, Lishner DM. Surplus or shortage? Unraveling the physician supply conundrum. West J Med 1991;154:43-50.

11. Ward S. Kansas women physicians respond to survey. Kansas Med 1993;94:224-7.

12. Rourke LL, Rourke J, Brown JB. Women family physicians and rural medicine. Can the grass be greener in the country? Can Fam Physician 1996;42: 1063-7, 1077-82.

13. Hecht RC, Farrell JG. Comparative profiles of rural and urban family physicians-based upon 100 graduates of the University of Wisconsin family practice residency programs. Wis Med J 1983;82:21-4.

14. Dickinson J, Hickner J, Radford S. The changing characteristics of rural GPs. Aust Fam Physician 1995;24:1272-8.

15. Martin SC, Parker RM, Arnold RM. Careers of women physicians - choices and constraints. West J Med 1988;149:758-60.

16. Ogle KS, Henry RC, Durda K, Zivick JD. Genderspecific differences in family practice graduates. $J$ Fam Pract 1986;23:357-60.

17. SPSS release 4.0 for Macintosh. Chicago, SPSS, Inc, 1993.

18. Glaser BG. Emergence versus forcing: basics of grounded theory analysis. Mill Valley, Calif: Sociology Press, 1992.

19. Anderson EA, Bergeron D, Crouse BJ. Recruitment of family physicians in rural practice. Minn Med 1994;77:29-32. 